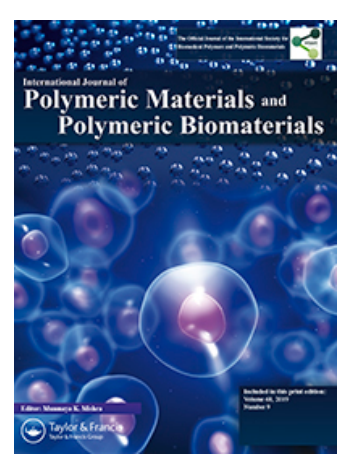

International Journal of Polymeric Materials and Polymeric Biomaterials

\title{
Chitosan impregnated gutta-percha points: antimicrobial in vitro evaluation and mechanical properties
}

\author{
Alejandra Cardelle-Cobas, Patrícia J. M. Reis, Eduardo Costa, Freni K. Tavaria \\ \& Manuela E. Pintado
}

To cite this article: Alejandra Cardelle-Cobas, Patrícia J. M. Reis, Eduardo Costa, Freni K. Tavaria \& Manuela E. Pintado (2019) Chitosan impregnated gutta-percha points: antimicrobial in vitro evaluation and mechanical properties, International Journal of Polymeric Materials and Polymeric Biomaterials, 68:9, 481-488, DOI: 10.1080/00914037.2018.1466134

To link to this article: https://doi.org/10.1080/00914037.2018.1466134

\section{Published online: 03 Jul 2018.}

Submit your article to this journal $₫$

Џlll Article views: 104

Q View related articles $\longleftarrow$

View Crossmark data ־ 


\title{
Chitosan impregnated gutta-percha points: antimicrobial in vitro evaluation and mechanical properties
}

\author{
Alejandra Cardelle-Cobas, Patrícia J. M. Reis, Eduardo Costa, Freni K. Tavaria (D) and Manuela E. Pintado (iD \\ Universidade Católica Portuguesa, Centro de Biotecnologia e Química Fina - Laboratório Associado, Escola Superior de Biotecnologia, \\ Porto, Portugal
}

\begin{abstract}
Chitosan-impregnated gutta-percha points (ChitGPP) were tested for their ability to inhibit the growth of microorganisms usually involved in root canal infections. Their mechanical properties were also studied and compared with the commonly used commercial points in endodontics. ChitGPP were more efficient in reducing the microbial load than those without chitosan. ChitGPP also possess better tensile and elastic properties than commercial ones. After six months of storage, ChitGPP's were still able to reduce the bacterial load by 1 log, suggesting that impregnation of gutta-percha points with chitosan could be a good alternative to obtain gutta-percha points with improved antimicrobial properties.
\end{abstract}

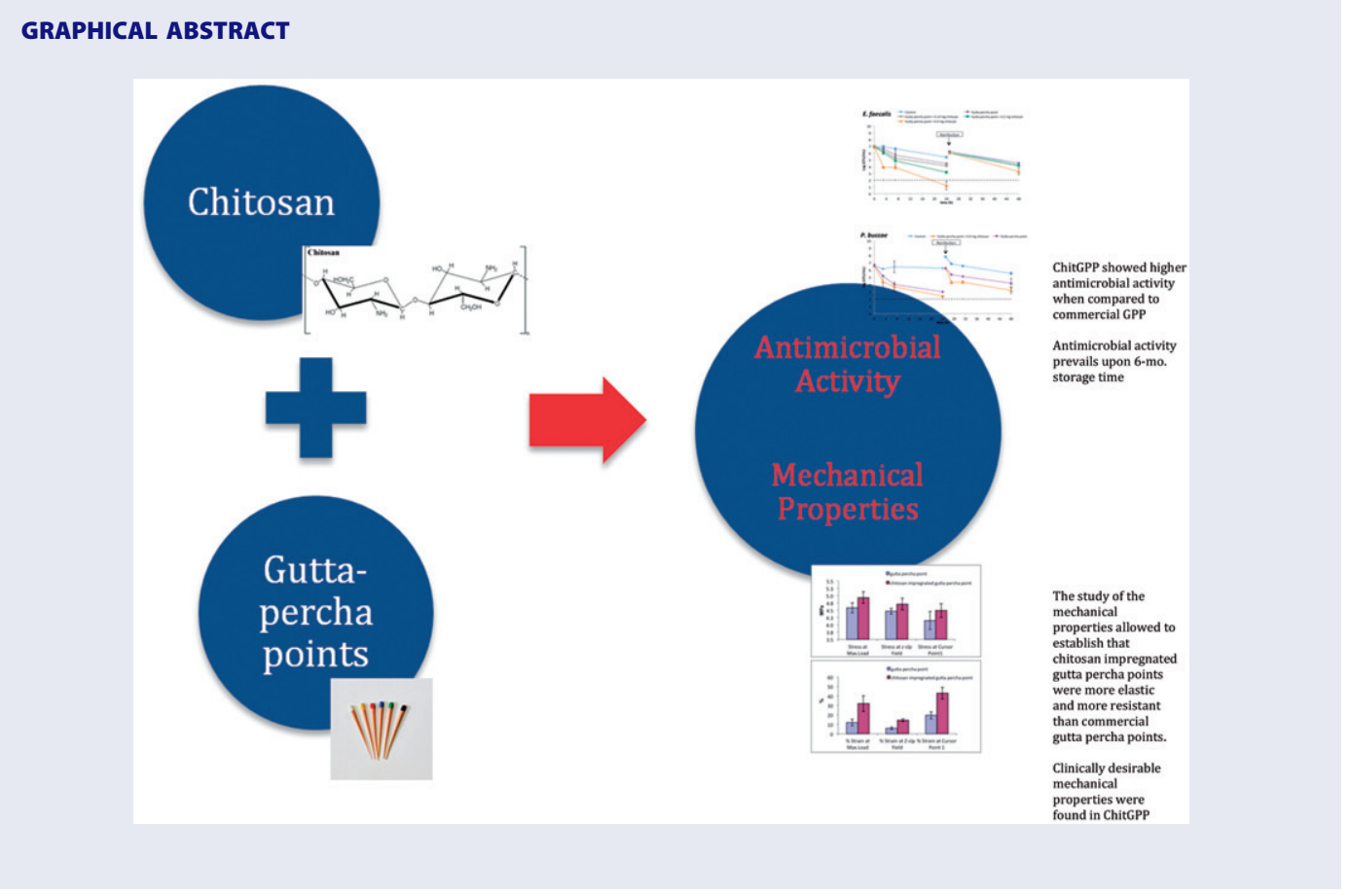

\section{ARTICLE HISTORY}

Received 11 December 2017 Accepted 14 April 2018

\section{KEYWORDS}

Antimicrobial activity; chitosan; endodontic treatment; gutta-percha; mechanical properties; root canal filling materials

\section{Introduction}

Microorganisms are the major etiological agents in pulpal and periapical disease. In case of primary endodontic infections the main etiological agents consists mainly of strict anaerobes. However, in cases of failed endodontic treatment, the intracanal microflora is altered and facultative anaerobes predominate ${ }^{[1,2]}$. The efficient control and elimination of microorganisms are very important during endodontic treatment because of their role in these diseases. Biomechanical preparation of infected root canals using chemical substances with antimicrobial activity can eliminate most of the microorganisms present, although some may remain in the root canal system, dentinal tubules or apical resorption craters, thus forming an apical bacterial biofilm. In these cases, intracanal medication is necessary to completely eliminate them ${ }^{[3,4]}$. Thus, two of the main goals of the endodontic therapy are the elimination of microorganisms from the root canal system and the prevention of subsequent reinfection ${ }^{[5]}$. For this purpose, gutta-percha cones are the most universally accepted filling material due to their desirable properties 
such as biological compatibility, pliability, dimensional stability, radiopacity, and easy removal from the canal when required. Evidence of slight antibacterial activity for guttapercha cones exists and it is known to be due to the zinc oxide $(\mathrm{ZnO})$, the major component of the cones ${ }^{[6]}$. However, the effect is too weak and limited for this material to be an effective antimicrobial agent. Otherwise, most currently used root canal filling materials do not possess a complete seal, which may contribute to treatment failures via re-colonization by bacteria and recontamination of the canal system. Enterococcus faecalis has been classified as one of the most resistant oral pathogens, especially in secondary and persistent root canal infections ${ }^{[7]}$. Anaerobic species such as Peptostreptococcus micros, Porphyromonas gingivalis, Porphyromonas endodontalis, Prevotella intermedia, and Prevotella nigrescens have also been found in teeth with failing endodontic treatment ${ }^{[8]}$. On the other hand, Candida albicans has been the fungal species most often detected in these infections ${ }^{[9]}$.

Different compositions of gutta-percha cones have been previously studied by several authors: although calcium hydroxide $\left(\mathrm{Ca}(\mathrm{OH})_{2}\right)$ and $\mathrm{ZnO}$ are widely recognized in the dental practice as the antimicrobials of choice, $\mathrm{Ca}(\mathrm{OH})_{2}, \mathrm{ZnO} /$ chlorhexidine, or $\mathrm{ZnO} /$ iodine-polyvinyl-pyrrolidonecontaining gutta-percha cones failed to effectively inhibit endodontic pathogens in root canals ${ }^{[10]}$. In other studies, gutta-percha cones containing chlorhexidine presented antimicrobial activity whereas gutta-percha cones containing $\mathrm{Ca}(\mathrm{OH})_{2}$ did not ${ }^{[11]}$. Similar results were attained in the studies by Decurcio et al. ${ }^{[12]}$ and Öztan et al. ${ }^{[13]}$. The latter revealed that gutta-percha points containing a mixture of $\mathrm{Ca}(\mathrm{OH})_{2}$ and chlorhexidine diacetate have higher efficacies than $\mathrm{Ca}(\mathrm{OH})_{2}$ or chlorhexidine diacetate alone against $\mathrm{C}$. albicans, C. tropicalis, and Saccharomyces cerevisiae. According to Vijay et al. ${ }^{[14]}$, tetracycline-impregnated gutta-percha offers maximum antibacterial advantage over $\mathrm{Ca}(\mathrm{OH})_{2}$ and traditional gutta-percha against $E$. faecalis. Shur et al. ${ }^{[15]}$ showed that iodoform-containing gutta-percha cones had an in vitro inhibitory effect against $S$. aureus and Fusobacterium nucleatum but not against E. faecalis, E.coli and Pseudomonas aeruginosa.

Chitosan, a natural and non-toxic polymer, is produced by the deacetylation of chitin and has received considerable attention in a wide range of applications due to their biological (anti-microbial, bio-adhesive, bio-compatible, and binding agent) properties ${ }^{[16]}$. Applications of the antimicrobial activity of chitosan are currently investigated in food, textile, and cosmetic industries and in medicine, including dentistry ${ }^{[17-21]}$. In addition, natural bioactive materials have recently been investigated as promising agents to prevent oral diseases such as dental caries. Chitosan showed antibacterial properties against oral bacterial pathogens ${ }^{[22-25]}$. Furthermore, recent studies demonstrated that water-soluble reduced chitosan, used as a mouth rinse solution, displayed an antibacterial and plaque-reducing action ${ }^{[26-29]}$. Chewing gum containing chitosan and chitosan derivatives, also effectively inhibited the growth of cariogenic bacteria in saliva $^{[30-32]}$. Chitosan nanoparticles were also tested for the loading of toothpaste bioactive compounds and adhesion on tooth analogs. Results showed that chitosan has a great potential to be used for the in situ release of the active compounds in a sustained manner ${ }^{[33,34]}$.

These advantages and applications of chitosan suggest its potential usage in root canal treatment and some authors have already carried out some preliminary assays in this field. Ahmed et al. ${ }^{[35]}$ developed chitosan films containing ciprofloxacin and diclofenac sodium for the topical treatment of periodontitis. However, in these studies chitosan was used as release material and not as the active ingredient. Moreover recently, DaSilva et al. ${ }^{[36]}$ and Carpio-Perochena et al. ${ }^{[37]}$ have reported the use of chitosan nanoparticles to inhibit biofilm formation and as an antibacterial agent when combined with root canal sealers. In this study, chitosan was directly used to impregnate gutta-percha cones and the antimicrobial and mechanical properties of Chitosan-impregnated gutta-percha points (ChitGPP) were demonstrated and compared with that of commercial available ones.

\section{Materials and methods}

\subsection{Microorganisms}

Gram-negative (Prevotella buccae CCUG 15401 (Culture Collection University of Göteborg, Sweden)), Porphyromonas gingivalis (generously donated by Dr. Cristina Pina, Universidade Fernando Pessoa), Gram-positive strict anaerobes (Peptostreptococcus stomatis CCUG 51858), a Grampositive facultative anaerobic bacteria (Enterococcus faecalis, from our culture collection), and a yeast (Candida albicans ATCC 18804), were used in the present study. All obligate anaerobic bacteria were grown in Wilkins-Chalgren agar (WC agar, Oxoid, Basingstoke, UK), E. faecalis was grown in M17 agar (Difco, Detroit, MI) and C. albicans was grown in potato dextrose agar (PDA, Lab M, Bury, UK). All bacterial strains were cultured at $37^{\circ} \mathrm{C}$, whereas only C. albicans was cultured at $30^{\circ} \mathrm{C}$. Anaerobes were incubated under anaerobic atmosphere in a GasPak jar (Becton-Dickinson, Heidelberg, Germany).

\subsection{Gutta-percha points and chitosan}

For the experiments, ISO 20 and IS0 60-sized gutta-percha points (Dentsply, UK) were used. Composition was previously described by Gurgel-Filho et al. ${ }^{[38]}$ as follows: $14.5 \%$ $(w / w)$ gutta-percha, $1.2 \%(w / w)$ resin, 28.0\% $(w / w)$ metal sulphates, 2.8\% (w/w) zinc chloride, and 56.3\% (w/w) ZnO. Chitosan (Low molecular weight (LMW), Sigma-Aldrich, St. Louis, MO) were used to impregnate the commercial gutta-percha points. To carry out the coating, a chitosan solution was prepared as follows: chitosan $(1.4-2 \%)$ was dissolved in $1 \%$ acetic acid $(v / v)$ and mixed with a plasticizer, specifically with $40 \%(v / v)$ of sorbitol solution. Then, the $\mathrm{pH}$ was adjusted to 5.8 to ensure that the antimicrobial effect caused by chitosan was not due to the low $\mathrm{pH}$ or the acid effect brought about by the acetic acid solution. The mixture was placed in a petri plate and were dried at $37^{\circ} \mathrm{C}$ until a dense solution was obtained, which was then 
used to coat the commercial gutta-percha points. After manual coating, the points were left to dry to obtain a film around the gutta-percha points and were stored in the dark until further analysis. The film was prepared as aforementioned, after drying, $0.14,0.20$, and $0.40 \mathrm{mg}$ of chitosan surrounding the gutta-percha points were obtained. These were weighed before and after impregnation.

\subsection{Antimicrobial activity}

The antimicrobial activity of gutta-percha points impregnated with chitosan was evaluated by determining the inhibition of microbial growth using a modified method developed by Podbielski et al. ${ }^{[10]}$ For this purpose, experimental inoculum of the different microorganisms ( $P$. buccae, $P$. gingivalis, $P$. stomatis, E. faecalis, and C. albicans) were obtained after overnight growth (ca. $10^{7} \mathrm{CFU} / \mathrm{mL}$ ) at $37^{\circ} \mathrm{C}$ in the appropriate growth conditions. Cells were then harvested by centrifugation at $2000 \times g$ for $10 \mathrm{~min}$ and re-suspended in the same volume of sterile $0.9 \%$ sodium chloride $(\mathrm{NaCl})$ solution. Aliquots $(100 \mu \mathrm{L})$ were then added to sterile $0.2 \mathrm{~mL}$ Eppendorf tubes containing three pieces of ChitGPP, previously cut and sterilized under ultraviolet light. Eppendorf tubes containing only microbial suspensions served as controls and different tubes were used for each sampling time. Un-impregnated guttapercha points (GPP) were also evaluated in the same way than those impregnated with chitosan. In order to avoid contaminations, separate tubes containing ChitGPP and GPP as well as controls were used for each sampling time. The tubes were maintained at $37^{\circ} \mathrm{C}$ and under aerobic or anaerobic conditions (GasPak, Heidelberg, Germany) according to the microorganism. The antimicrobial assay was carried out with $E$. faecalis and ISO 60-sized gutta-percha points impregnated with a solution containing $0.14 \mathrm{mg}$ of chitosan during $48 \mathrm{~h}$ and sampled at $0,1,3,5,7,18,24$, and $48 \mathrm{~h}$. Later, different amounts of chitosan $(0.14,0.2$, and $0.4 \mathrm{mg}$ ) contained in the ISO 60 sized ChitGPP were tested against $E$. faecalis in $24 \mathrm{~h}$ assays to evaluate the effect of the amount of chitosan.

The assays were repeated for $P$. buccae, $P$. gingivalis $P$. stomatis, and $C$. albicans, using the ISO 60 sized gutta-percha points impregnated with $0.4 \mathrm{mg}$ of chitosan during $24 \mathrm{~h}$ and sampled at $0,3,7$, and $24 \mathrm{~h}$. The reinfection event was simulated, by inoculation with $10^{9} \mathrm{CFU} / \mathrm{mL}$ to attain a final concentration of $10^{7} \mathrm{CFU} / \mathrm{mL}$. Samples were taken at $0,3,7$, and $24 \mathrm{~h}$ after re-infection. When the tubes were removed at each sampling time, they were vortexed for $15 \mathrm{~s}$ and aliquots $(10 \mu \mathrm{L})$ of the bacterial suspensions were serially diluted in $90 \mu \mathrm{L}$ sterile $0.9 \% \mathrm{NaCl}$ solution. Aliquots $(20 \mu \mathrm{L})$ of each dilution were plated onto the aforementioned solid medium depending of the microorganism. After incubation at $37^{\circ} \mathrm{C}$ for $48 \mathrm{~h}$, colonies were enumerated and $\mathrm{CFU} / \mathrm{mL}$ of suspension were calculated. Each experiment was performed in duplicate and on two independent experiments.

Efficacy of gutta-percha points after storage period was also evaluated. Thus antimicrobial activity of GPP and ISO 60-sized ChitGPP (0.14 mg LMWC) was evaluated against
E. faecalis after $0,1,3$, and 6 months of storage. Antimicrobial activity was evaluated as aforementioned after $7 \mathrm{~h}$ of infection (at the time of maximum effect of chitosan). All assays were carried out in triplicate.

\subsection{Mechanical properties}

ChitGPP and GPP were subjected to tensile tests using a Universal Testing machine (model 4501, Instron Corporation, Canton, MA) equipped with fixed grips and a $5 \mathrm{kN}$-static load cell operated according to the reference method $^{[39]}$. The initial grip separation was set at $50 \mathrm{~mm}$ and the crosshead speed was fixed at $4.8 \mathrm{~mm} / \mathrm{min}$. Tensile strength, elongation at break, and Young's modulus were determined in 18 independent cones using the Series IX Automated Materials Testing System software, v. 809.00 (Instron Corporation). In addition, the maximum force required to bend the ChitGPP and GPP to a 20-degree angle at a test diameter of $10 \mathrm{~mm}$ was recorded in 15 independent cones using a L\&W bending tester (Lorentzen \& Wettre, Kista, Sweden).

\subsection{Statistical analysis}

Statistical analyses were performed using SPSS v.24 software (SPSS, Chicago, IL) via one-way analysis of variance. The viable numbers of microorganisms $/ \mathrm{mL}$ were transformed into the $\log _{10}$ of the $\mathrm{CFU} / \mathrm{mL}$. Differences obtained at the $p<.05$ level were considered to be significant.

\section{Results}

\subsection{Antimicrobial activity}

Enterococcus faecalis was the selected microorganism to determine the best concentration to be used in impregnation, because it is a prevailing microorganism in the oral cavity and one which is very resistant to antimicrobials, besides sometimes is the only isolated microorganism from the oral cavity ${ }^{[40]}$. The first study encompassing the antimicrobial activity of ISO20 sized ChitGPP against E. faecalis was carried out for 14 days to evaluate the antimicrobial efficacy $(0.14 \mathrm{mg}$ of chitosan was used for impregnation). The results obtained (data not shown) indicated that, after $8 \mathrm{~h}$ the ChitGPP caused an important reduction (5 log-units) on bacterial cells in comparison with the control that showed an increase of bacterial cells of almost 3 log-units whereas and the un-impregnated gutta-percha points showed an increase of 0.5 log-units. After that, no significant reduction was observed with the bacterial counts remaining at ca. $2 \times 10^{7} \mathrm{CFU} / \mathrm{mL}$. After eight hours, bacterial counts in GPP slightly increased reaching ca. 11 log-units and after one day this value decreased down to $8 \log$-units and only after two days it reached the minimum value of 5 log-units (below that reached by ChitGPP). By three days, the viable cell numbers obtained for the three conditions reached the same value $(6.5 \mathrm{log})$, suggesting cell death under the conditions reported here. 
Although the antimicrobial effect of ISO 20-sized ChitGPP during the first $48 \mathrm{~h}$ of contact was clearly demonstrated, it was evident that the thin surface of the used gutta-percha point could only support on its surface a limited amount of chitosan $(0.14 \mathrm{mg})$, assuming the maximum dissolved concentration of $2 \%$. This amount induced a rapid reduction of $5 \log \mathrm{CFU} / \mathrm{mL}$ in the first $8 \mathrm{~h}$ so, it was interesting to evaluate if increasing the total gutta-percha surface would promote higher and faster antimicrobial effect. Hence, a new experiment was developed with ISO 60-sized points to establish the improved antimicrobial efficiency with the increased impregnation area. Additionally, it should be noted that these points are the basis to seal the root canal, since the technique implies the introduction in the first place of a major gutta-percha point more representative of the filling area and then filling the canal with those with a smaller size just to completely seal the spaces usually associated with cements. The results are featured in Figure 1; the treatment differences were all statistically significant $(p<0.05)$. The number of viable cells increased in the assays where guttapercha points were not included, starting to decrease after seven hours of inoculation. In the experiments where GPP were included, a lower value of bacterial cells was observed in comparison with control indicating that $E$. faecalis growth was inhibited in the presence of commercial gutta-percha points, remaining constant along the experiment with a value of ca. 6.5 log-units. In view of these results (14 days/ ISO 20-sized gutta-percha points and $48 \mathrm{~h} / \mathrm{ISO}$ 60-sized gutta-percha points), another experiment was conducted using the bigger sized gutta-percha points and timed experiments of 24 hours, since this is the period where major reductions were observed. It is well known that re-infection of root canal is a frequent problem in dentistry and for that, the use of materials that could prevent this reinfection, is very important. Thus, to simulate a re-infection in the root canal, the $24 \mathrm{~h}$ samples from the first experiment were inoculated in order to attain a bacterial concentration of ca. 6-7 log-units. Different amounts of chitosan $(0,0.14,0.2$, and $0.4 \mathrm{mg}$ ) included in the film covering the point were tested (Figure 2). Chitosan impregnated gutta-percha points showed higher antimicrobial activity than commercial ones;

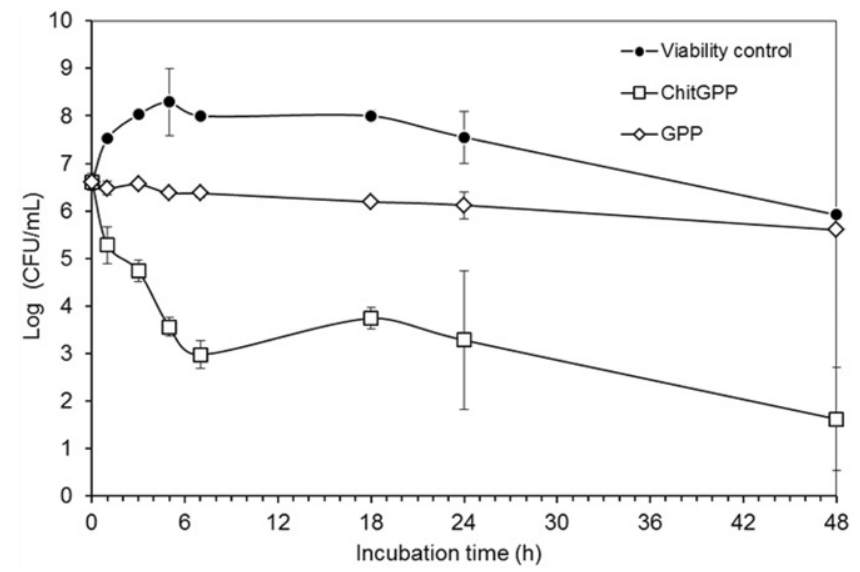

Figure 1. Antimicrobial activity of ISO 60 sized chitosan-impregnated gutta-percha points with $0.14 \mathrm{mg}$ of LMWC upon contact with E. faecalis during $48 \mathrm{~h}$. Vertical bars represent standard deviation $(n=4)$.

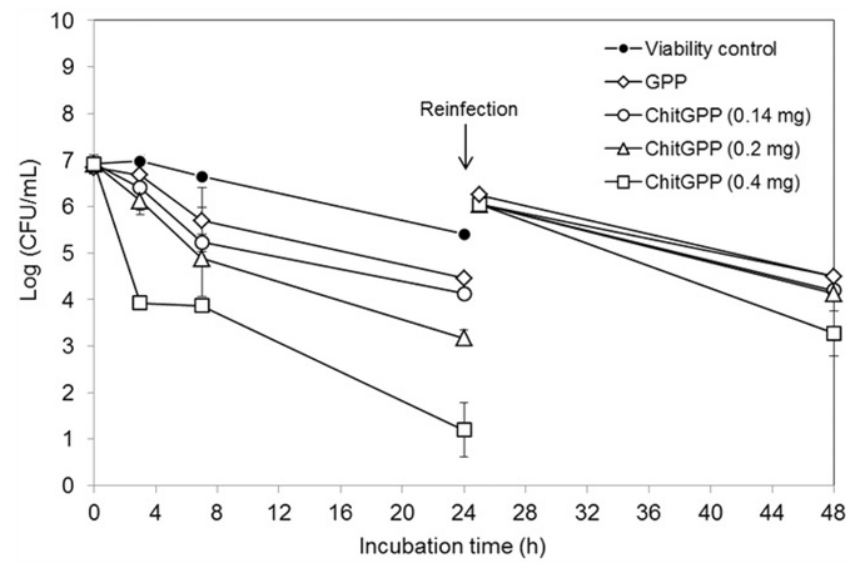

Figure 2. Antimicrobial activity of ISO 60 sized impregnated gutta-percha points with different amounts of $\operatorname{LMWC}(0.14,0.20$, and $0.40 \mathrm{mg})$ upon contact with $E$. faecalis during $48 \mathrm{~h}$. Reinfection was applied $24 \mathrm{~h}$ after the first infection. Vertical bars represent standard deviation $(n=4)$.

the antimicrobial activity increased with the amount of chitosan used for the impregnation and impregnated gutta-percha points with $0.4 \mathrm{mg}$ of chitosan showed a microbial reduction of $6 \log$-units during the first $24 \mathrm{~h}$ of the assay. After reinfection, no significant differences $(p>0.05)$ were found between GPP and ChitGPP with 0.14 and $0.2 \mathrm{mg}$ of chitosan. However, Gutta-percha points with $0.4 \mathrm{mg}$ of chitosan showed, significant differences $(p<0.05)$ and continued to show antimicrobial activity especially after $24 \mathrm{~h}$ of reinfection.

In view of this, points with $0.4 \mathrm{mg}$ of chitosan were selected as displaying the best amount for the impregnation and similar assays were carried out with $P$. buccae, $P$. gingivalis, and $P$. stomatis and as well with the yeast C. albicans, which usually causes infection in the root canal. Figure 3a shows the results obtained for $P$. buccae. In this case, results obtained from the assays with ChitGPP, GPP and the control were statistically different (except at $7 \mathrm{~h}$ were the differences between GPP and ChitGPP were not significant). An important reduction ( $\sim 5$ log-units) of the numbers of $P$. buccae was found for GPP and ChitGPP after $24 \mathrm{~h}$ after inoculation, contrasting with almost no decrease for the control. After reinfection, differences between ChitGPP and GPP were more accentuated and significantly different $(p<0.05)$ with ChitGPP showing greater effectiveness than commercial points.

During the in vitro antimicrobial assays carried out against $P$. gingivalis (Figure $3 \mathrm{~b}$ ), GPP only started to show activity after $7 \mathrm{~h}$ of contact with the bacteria, however the difference with respect to the control was not significant $(p>0.05)$. In contrast, ChitGPP showed to be active immediately after infection. After $7 \mathrm{~h}$, a reduction of 7 log-units in the bacterial counts was achieved. After reinfection, both types of gutta-percha points, (ChitGPP and GPP) showed a similar pattern in bacterial reduction for $P$. gingivalis with no significant differences between the two treatments.

Results obtained for P. stomatis (Figure 3c), showed a noticeable antimicrobial activity of ChitGPP; a $3 \log$-unit reduction was obtained during the first $7 \mathrm{~h}$ of infection and 6 logs after $24 \mathrm{~h}$. GPP only showed a slight decrease in 

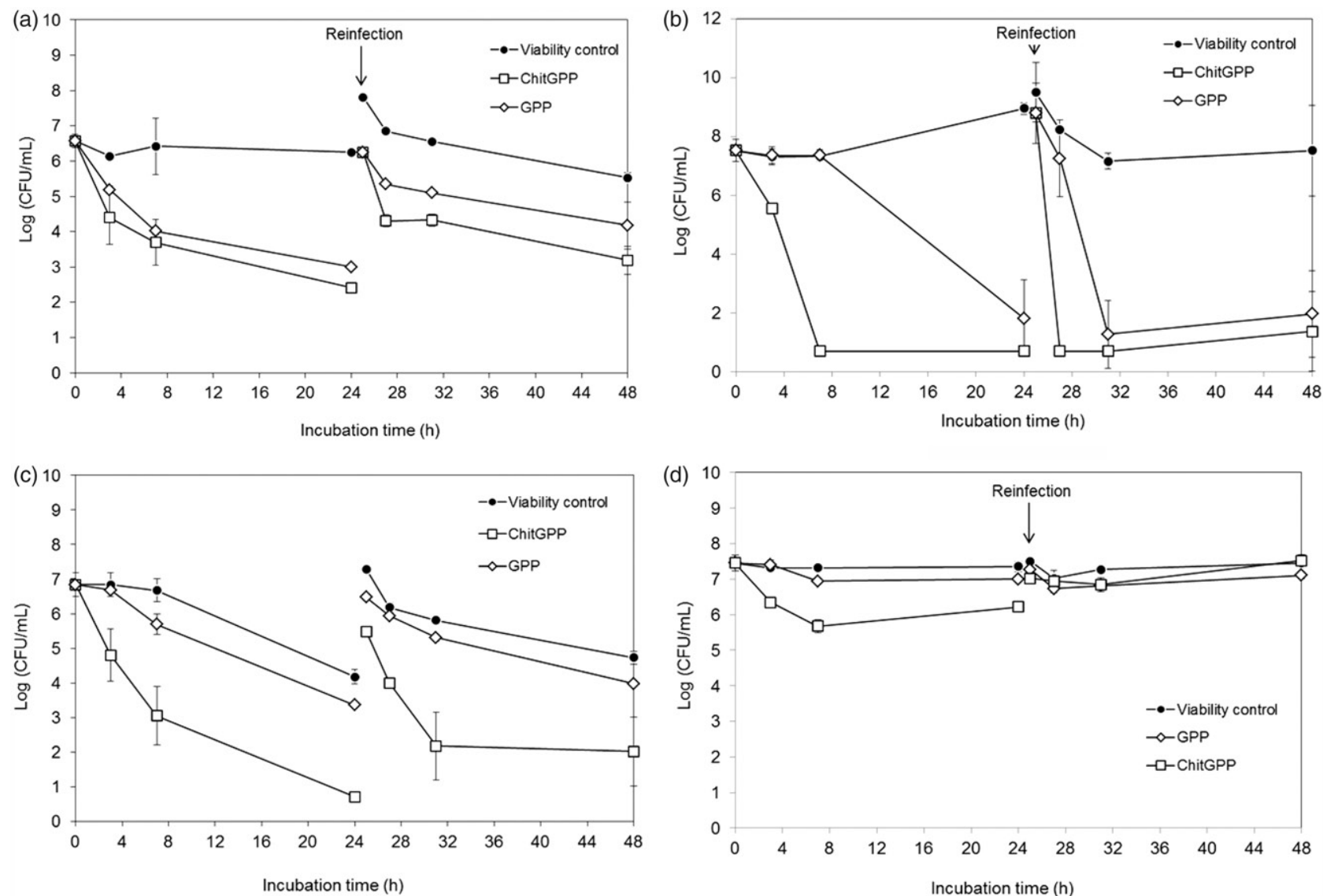

Figure 3. Survival of E. faecalis (a), P. buccae (b), P. gingivalis (c), P. stomatis (d), and C. albicans (e) when in contact with ISO 60 sized impregnated gutta-percha points with $0.4 \mathrm{mg}$ of LMWC during $48 \mathrm{~h}$. Reinfection was applied $24 \mathrm{~h}$ after the first infection. Vertical bars represent standard deviation $(n=4)$.

bacterial counts. After reinfection ChitGPP maintained its antimicrobial activity $(p<0.05)$ and a 5 log-unit reduction in the bacterial counts was achieved by $30 \mathrm{~h}$.

Figure $3 \mathrm{~d}$ shows the antifungal in vitro assays carried out with C. albicans and ChitGPP with $0.4 \mathrm{mg}$ of chitosan. Results showed a significant decrease throughout time, up to $27 \mathrm{~h}$ on fungal survival with respect to the assays done with non-impregnated points. However, by $48 \mathrm{~h}$ no significant differences were found when compared to the control. Maximum reduction was obtained seven hours after impregnation and only a 2 log-unit reduction was achieved.

\subsection{Effect of storage in the antimicrobial activity of chitosan impregnated gutta-percha points}

The effect of the storage on the antimicrobial activity of ISO 60-sized ChitGPP and GPP against E. faecalis was also evaluated. Figure 4 shows the results obtained for 0,1 , and 6 months of storage, respectively. ChitGPP (non-stored), showed to possess a reduction capacity on the bacterial charge of ca. 3.5 log-units whereas GPP did not show a significant decrease of the viable cell numbers. After 1 month of storage, ChitGPP was able to reduce the microbial load by only 2 logs with respect to the control. However, GPP showed a slight increase in its capacity to reduce the microbial load and showed a reduction of 0.5 logs with respect to the control, perhaps due to liberation of $\mathrm{ZnO}$ upon storage $(p<0.05)$. After six months, the ChitGPP was able to reduce the bacterial load by $1 \log$, whereas GPP maintained its reduction capacity at $0.5 \operatorname{logs}(p<0.05)$. These results suggest that partial degradation of gutta-percha points might be occurring $^{[41]}$ or in the film surrounding the gutta-percha points ${ }^{[42]}$ and probably other assays should be carried out to confirm this. Despite this, results were always better than those obtained for commercial points.

\subsection{Mechanical properties}

The main mechanical properties (tensile strength, elongation, and bending force) were evaluated to determine if chitosan could affect these properties in commercial gutta-percha points and, consequently, become more suitable to be used in root canal treatments. The impregnation of commercial gutta-percha points with chitosan provided enhanced resistance to deformation/rupture. As can be observed in Table 1, significantly higher values for tensile strength (ultimate and yield strength) were found in ChitGPP. When ChitGPP was placed under tensile stress they elongated more as shown by the significantly high maximum elongation values obtained. Thus, they retained the most ductility, a useful clinical characteristic for filling materials. To examine flexural rigidity, a bending test was conducted, although no significant differences were obtained with respect to the force required to bend the points to a 20-degree angle. However, ChitGPP showed statistically significant differences for elasticity when compared to commercial ones. Young modulus was found to be 


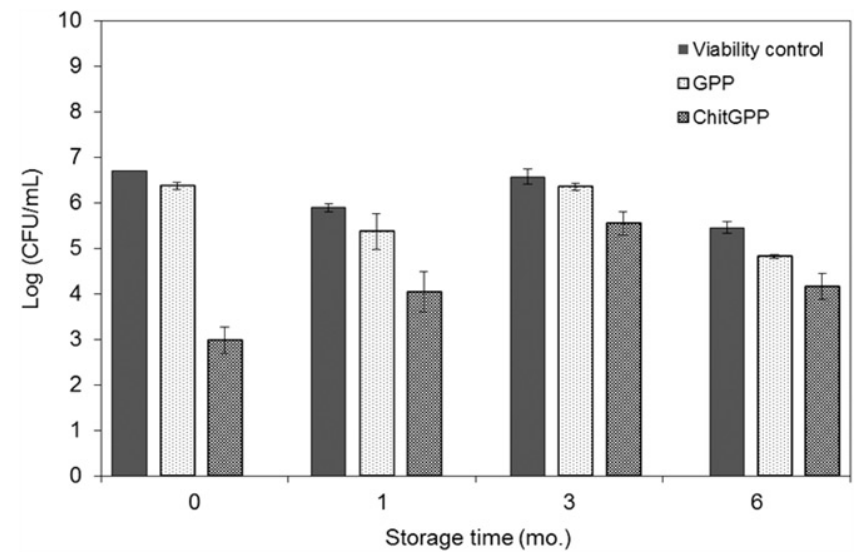

Figure 4. Effect of storage on ISO 60 sized chitosan (0.14 mg LMW)-impregnated gutta-percha points against $E$. faecalis in quantitative in vitro assays set for $7 \mathrm{~h}$ (initial viable cell counts of $10^{6}-10^{7} \mathrm{CFU} / \mathrm{mL}$ ). (a) 0 months, (b) 1 month, (c) 3 months, and (d) 6 months of storage at room temperature and dark conditions. Vertical bars represent standard deviation $(n=4)$.

significantly higher for GPP than for ChitGPP, indicating that the former are less elastic than those impregnated with chitosan.

\section{Discussion}

\subsection{Antimicrobial activity}

The first screening encompassing the antimicrobial activity of ISO 20-sized ChitGPP were carried out against E. faecalis, the microorganism were most frequently found in endodontic infections, especially in secondary and persistent root canal infections ${ }^{[43]}$. The fact that GPP showed a higher antimicrobial activity than ChitGPP can be due to the partial dissolution of the components of the ISO 20-sized gutta-percha points with antimicrobial activity such as $\mathrm{ZnO}$. This is apparent, once the effect is not immediate as for chitosan, since $\mathrm{ZnO}$ requires a certain time to get dissolved, explaining the absence of effect until $8 \mathrm{~h}$ and the increasing inhibition effect from $8 \mathrm{~h}$ onwards. The ISO 20-sized points are very thin and the contact with the saline solution during the experiment allowed the release of such components, a scenario that could also occur in vivo conditions in the root canal. The literature reports that, although added to gutta-percha points primarily for mechanical stability reasons, $\mathrm{ZnO}$ alone possesses antimicrobial activity, thus decreasing bacterial counts ${ }^{[44]}$. Antimicrobial activity of $\mathrm{ZnO}$ alone was described for some endodontal pathogens such as P. micros, Veillonella parvula, Prevotella melaninogenica, Streptococcus mutans, and $P$. aeruginosa, a result similar to that found in this study. This effect can be attributed to the toxicity of the metal ion $\mathrm{Zn}^{2+[45]}$. In the case of ChitGPP, the film around the point could be acting as a protective barrier thus hindering the liberation of $\mathrm{ZnO}$, but assuring the antimicrobial effect through chitosan. As a result, the preliminary screening showed a fast bactericidal effect (reductions higher than $3 \log$ cycles) in less than $8 \mathrm{~h}$. Results obtained with ChitGPP were similar to those obtained by Podbielski et al. ${ }^{[46]}$ with the other gutta-percha points containing $\mathrm{Ca}(\mathrm{OH})_{2}$, a mixture of $\mathrm{ZnO}$ and chlorhexidine $(\mathrm{ZnO} / \mathrm{CHX})$, iodine-polyvinylpyrrolidone ( $\mathrm{ZnO} / \mathrm{I}-\mathrm{PVP})$, or a mixture of $\mathrm{CHX}$ and
Table 1. Mean ( \pm standard deviation) of mechanical properties of the chitosan-impregnated and un-impregnated gutta-percha points.

\begin{tabular}{lcc}
\hline & \multicolumn{2}{c}{ Gutta-percha point } \\
\cline { 2 - 3 } Parameter & $\begin{array}{c}\text { Chitosan- } \\
\text { impregnated }\end{array}$ & $\begin{array}{c}\text { Chitosan } \\
\text { un-impregnated }\end{array}$ \\
\hline Ultimate tensile strength, MPa & $4.935 \pm 0.440^{\mathrm{a}}$ & $4.579 \pm 0.367^{\mathrm{b}}$ \\
Tensile yield strength, MPa & $4.712 \pm 0.430^{\mathrm{a}}$ & $4.466 \pm 0.217^{\mathrm{b}}$ \\
Rupture strength, MPa & $4.489 \pm 0.510^{\mathrm{a}}$ & $4.148 \pm 0.669^{\mathrm{a}}$ \\
Tensile elongation, \% & $31.90 \pm 17.89^{\mathrm{a}}$ & $11.97 \pm 7.727^{\mathrm{b}}$ \\
Yield elongation, \% & $14.32 \pm 3.00^{\mathrm{a}}$ & $5.775 \pm 3.118^{\mathrm{b}}$ \\
Maximum elongation, \% & $42.97 \pm 12.97^{\mathrm{a}}$ & $19.49 \pm 7.946^{\mathrm{b}}$ \\
Young modulus, MPa & $65.41 \pm 14.6^{\mathrm{a}}$ & $160.9 \pm 23.924^{\mathrm{b}}$ \\
Bending force, mN & $0.119 \pm 0.012^{\mathrm{a}}$ & $0.115 \pm 0.008^{\mathrm{a}}$ \\
\hline
\end{tabular}

$\overline{\mathrm{a}, \mathrm{b}}$ The letters denote statistical significance $(p<0.05)$.

$\mathrm{I}-\mathrm{PVP}$ and $\mathrm{ZnO}(\mathrm{ZnO} / \mathrm{CHX} / \mathrm{I}-\mathrm{PVP})$. This indicates that chitosan, incorporated in lower amounts than the other medications provided the same antimicrobial activity against the tested microorganisms than the other studied gutta-percha points, thus reflecting greater efficacy. Chlorhexidine and chitosan have the same mechanism of antimicrobial activity, as both disrupt the bacterial cell membrane, leading to cell death ${ }^{[22,47]}$

Candida albicans is the most common commensal and pathological yeast found in the oral cavity ${ }^{[48]}$ and, for this reason, it was included in this study. It has been demonstrated that Candida species are resistant to some medications commonly used in endodontics, such as $\mathrm{Ca}(\mathrm{OH})_{2}$. Ferguson et al. ${ }^{[49]}$ evaluated the antifungal activity of aqueous $\mathrm{Ca}(\mathrm{OH})_{2}$ and found that $\mathrm{Ca}(\mathrm{OH})_{2}$ was only effective as a paste in direct contact with $C$. albicans. Other assays carried out with saturated $\mathrm{Ca}(\mathrm{OH})_{2}$ solution showed that the alkalinity of saturated $\mathrm{Ca}(\mathrm{OH})_{2}$ solution may not have a sufficient effect on C. albicans. In addition, $\mathrm{Ca}(\mathrm{OH})_{2}$ solution may readily display the $\mathrm{Ca}^{2+}$ ions necessary for the growth and morphogenesis of Candida ${ }^{[50,51]}$. These mechanisms may explain why $\mathrm{Ca}(\mathrm{OH})_{2}$ has been found to be ineffective against C. albicans.

Chitosan however, is known to be effective against a wide variety of fungi including C. albicans. C. albicans has shown to be susceptible to high and LMW chitosans having MW $>32 \mathrm{kDa}^{[29,52,53]}$ and even to sub-mic concentrations of oligochitosan $^{[54]}$, which suppressed the formation of hyphal structures, causing severe cell wall alterations. Results obtained by Öztan et al. ${ }^{[13]}$ showed that only the points containing $\mathrm{Ca}(\mathrm{OH})_{2}$ and chlorhexidine were effective against the Candida species used in their study. Specifically for C. albicans results showed a total reduction after two days of incubation. After $24 \mathrm{~h}, 4 \log$ units were reduced, twice the reduction obtained in our study with chitosan-impregnated gutta-percha points. In comparison with bacteria, very little is known about the ways in which fungi can circumvent the action of antimicrobials.

\subsection{Mechanical properties}

The study of the mechanical properties allowed establishing that the impregnation of gutta-percha points with chitosan improved its mechanical properties (higher values for tensile strength and elongation) providing enhanced resistance to 
fracture. An increase in tensile strength has been reported as a clinically desirable characteristic so that it reflects the ability to retrieve a snugly inserted point completely. Cones with low percentages of gutta percha have poorer plasticity, allowing for a poorer apical sealing as reported by Gurgel-Filho et al. ${ }^{[5]}$ Gutta percha cones also present higher elastic modulus than other materials (e.g., Resilon) ${ }^{[41]}$, which translates in less flexibility under the same loading force (needing more force to adapt to root canal walls). The lack of rigidity and adhesivity of gutta cones have been quoted as some of the disadvantages for its use, hindering its use in small canals. From early on, Friedman et $\mathrm{al}^{[56]}$ reported that root canal filling material should possess the proper combination of flexibility and rigidity to permit the negotiation of almost any root canal. Mechanical properties of individual brands were found to be a function of the gutta-percha and $\mathrm{ZnO}$ concentration ${ }^{[57]}$. The impregnation with chitosan, as reported here, seems to improve some of the drawbacks in the mechanical properties of gutta percha points.

\section{Conclusion}

From the results of the present study, it can be concluded that chitosan impregnated gutta-percha points showed a higher (and significant) antimicrobial and antifungal activities and improved mechanical properties when compared to commercial gutta-percha points. The in vitro simulations of infection in the root canal showed that chitosan impregnated gutta-percha points were able to maintain their antimicrobial capacity throughout time. This activity was more pronounced towards $P$. buccae, $P$. stomatis, and $P$. gingivalis.

In brief, these results show, that the use of chitosan impregnated gutta-percha points could be an interesting alternative to commercial gutta-percha points. Chitosan demonstrated an important antimicrobial effect in this application reinforcing the action of gutta-percha points. However, more studies including chitosan in the formulation of gutta-percha points should be developed, especially exploiting its action against fungi and future research needs to be conducted to evaluate the antimicrobial efficacy of medicated gutta-percha points under clinical conditions.

\section{Acknowledgments}

We would like to thank the scientific collaboration of CBQF under the FCT project UID/Multi/50016/2013.

\section{Funding}

This project was funded under the Project - Quitoral: development of new chitosan formulations for application in oral medicine [QRENADI 3474]. Financial support for A. Cardelle-Cobas was obtained via Fundação para a Ciência e Tecnologia (FCT, Portugal) through a postdoctoral grant [SFRH/BPD/90069/2012].

\section{ORCID}

Freni K. Tavaria (iD http://orcid.org/0000-0002-6273-6668 Manuela E. Pintado (D) http://orcid.org/0000-0002-0760-3184

\section{References}

[1] Molander, A.; Reit, C.; Dahl, N. G.; Kvist, T. Int. Endod. J. 1998, 31, 1 .

[2] Lana, M. A.; Ribeiro-Sobrinho, A. P.; Stehling, R.; Garcia, G. D.; Silva, B. K. C.; Hamdan, J. S.; Nicoli, J. R.; Carvalho, M. A. R.; Farias, L. M. Oral Microbiol. Immunol 2001, 16, 100.

[3] Torabinejad, M.; Turman, M. J. Endodont. 2011, 37, 265.

[4] El-Hadi, T.; Sorrentino, T.; Calmels, M. N.; Fraysse, B.; Deguine, O.; Marx, M. Otol. Neurotol. 2012, 33, 591.

[5] Bodrumlu, E.; Alacam, T. J. Can. Dent. Assoc. 2006, 72, 733.

[6] Gurgel, E. D.; Feitosa, J. P. A.; Teixeira F. B.; de Paula R. C. M.; Silva, J. B. A.; Souza, F. J. Int. Endod. J. 2003, 36, 302.

[7] Stuart, C. H.; Schwartz, S. A.; Beeson, T. J.; Owatz, C. B. J. Endodont. 2006, 32, 93.

[8] Blome, B.; Braun, A.; Sobarzo, V.; Jepsen, S. Oral. Microbiol. Immunol 2008, 23, 384.

[9] Siqueira, J. F.; Sen, B. H. Oral Surg. Oral Med. Oral Pathol. Oral Radiol. Endod. 2004, 97, 632.

[10] Podbielski, A.; Boeckh, C.; Haller, B. J. Endodont. 2000, 26, 398.

[11] Tanomaru, J. M.; Pappen, F. G.; Tanomaru Filho, M.; Spolidorio, D. M.; Ito, I. Y. Braz. Oral Res. 2007, 21, 35.

[12] Decurcio, D. A.; Crosara, M. B.; Silva, J. A.; Amorim, L. F. G.; Estrela, C. R. A. Rev. Odont. Brasil Central. 2010, 18, 30.

[13] Öztan, M.D.; Kiyan, M.; Gerçeker, D. Oral Surg. Oral Med. Oral Pathol. Oral Radiol. Endod. 2006, 102, 410.

[14] Vijay, R.; Suman, M.; Shashikala, K. Indian J. Dent. Adv. 2010, 2 , 248.

[15] Shur A. L.; Sedgley, C. M.; Fenno, J. C. Int. Endod. J. 2003, 36, 616.

[16] Kong, M.; Chen, X. G.; Xing, K.; Park, H. J. Int. J. Food Microbiol. 2010, 144, 51.

[17] Tsai, G. J.; Su, W. H. J. Food Prot. 1999, 62, 239.

[18] Khor, E.; Lim, L. Y. Biomaterials. 2003, 24, 2339.

[19] Cooksey, K. Food Addit. Contam. 2005, 22, 980.

[20] Kenawy, E. R.; Worley, S. D.; Broughton, R. Biomacromolecules. 2007, 8, 1359.

[21] Park, B. K.; Kim, M. M. Int. J. Mol. Sci. 2010, 11, 5153.

[22] Helander, I. M.; Nurmiaho-Lassila, E. L.; Ahvenainen, R.; Rhoades, J.; Roller, S. Int. J. Food Microbiol. 2001, 71, 235.

[23] Rabea, E. I.; Badawy, M. E. T.; Stevens, C. V.; Smagghe, G.; Steurbaut, W. Biomacromolecules. 2003, 4, 1457.

[24] Tang, H.; Zhang, P.; Kieft, T. L.; Ryan, S. J.; Baker, S. M.; Wiesmann, W. P.; Rogelj, S. Acta. Biomaterials. 2010, 6, 2562.

[25] Costa, E. M.; Silva, S.; Pina, C.; Tavaria, F. K.; Pintado, M. M. Anaerobe. 2012, 18, 305.

[26] Sano, H.; Shibasaki, K.; Matsukubo, T.; Takaesu, Y. Bull. Tokyo Dent. Coll. 2001, 42, 251.

[27] Sano, H.; Shibasaki, K.; Matsukubo, T.; Takaesu, Y. Bull. Tokyo Dent. Coll. 2003, 44, 9.

[28] Bae, K.; Jun, E. J.; Lee, S. M.; Paik, D. I.; Kim, J. B. Clin. Oral Invest. 2006, 10, 102.

[29] Costa, E. M.; Silva, S.; Madureira, A. R.; Cardelle-Cobas, A.; Tavaria, F. K.; Pintado, M. M. Carbohyd. Polym. 2014, 101, 1081.

[30] Hayashi, Y.; Ohara, N.; Ganno, T.; Ishizaki, H.; Yanagiguchi, K. J. Dent. 2007, 35, 871 .

[31] Hayashi, Y.; Ohara, N.; Ganno, T.; Yamaguchi, K.; Ishizaki, T.; Nakamura, T.; Sato, M. Arch. Oral Biol. 2007, 52, 290.

[32] Miao, D.; Blom, D.; Zhao, H.; Luan, X.; Chen, T.; Wu, X.; Song, N. J. Nanjing Med. University. 2009, 23, 69.

[33] Kockisch, S.; Rees, G. D.; Tsibouklis, J.; Smart, J. D. Eur. J. Pharm. Biopharm. 2005, 59, 207.

[34] Liu, H.; Chen, B.; Mao, Z.; Gao, C. J. Appl. Polym. Sci. 2007, 106,4248

[35] Ahmed, M. G.; Harish, N. M.; Charyulu, R. N.; Prabhu, P. Trop. J. Pharm. Res. 2009, 8, 33.

[36] DaSilva, L.; Finer,Y.; Friedman, S.; Basrani, B. J. Endod. 2013 39, 249.

[37] Carpio-Perochena, A.; Kishen, A.; Shrestha, A.; Bramante, C.M. J. Endod. 2015, 41, 1353. 
[38] Gurgel-Filho, E.D.; Andrade Feitosa, J.P.; Teixeira, F.B.; Monteiro de Paula, R.C.; Araújo Silva, J.B.; Souza-Filho, F.J. Int. Endod. J. 2003, 36, 302.

[39] ASTM-D412-98a. Philadelphia: The American Society for Testing and Materials (ASTM) Standards, 2002.

[40] Lui, J.N.; Sae-Lim, V.; Song, K.P.; Chen. N.N. Int. Endod. J. 2004, 37, 105.

[41] Khedmat, S.; Aghajani, F.; Zaringhalam, S. J. Dent. Tehran Univ. Med. Sci. 2013, 10, 548.

[42] Szymańska, E.; Winnicka, K. Mar. Drugs. 2015, 13, 1819.

[43] Peciuliene, V.; Balciuniene, I.; Eriksen, H. M.; Haapasalo, M. J. Endodont. 2000, 26, 593.

[44] Tchaou, W. S.; Turng, B. F.; Minah, G. E.; Coll, J. A. Pediatr. Dent. 1996, 18, 444.

[45] Silver, S. Gene. 1996, 179, 9.

[46] Podbielski A.; Spahr, A.; Haller, B. J. Endodont. 2003, 29, 340.

[47] Castillo, J.A.; Clapés, P.; Infante, M.R.; Comas, J.; Manresa, Á. J. Antimicrob. Chemother. 2006, 57, 691.

[48] Fotos, P.; Hellstein, J. Dent. Clin. North Am. 1992, 36, 857.

[49] Ferguson, J. W.; Hatton, J. F.; Gillespie, M. J. J. Endodont. 2002, 28,68 .
[50] Waltimo, T. M. T.; Sirén, E. K.; Orstavik, D.; Haapasalo, M. P. P. Int. Endod. J. 1999, 32, 94.

[51] Sen, B. H.; Akdeniz, B. G.; Denizci, A. A. Oral Surg. Oral Med. Oral Pathol. Oral Radiol. Endod. 2000, 90, 651.

[52] Tayel, A. A.; Moussa, S.; El-Tras, W. F.; Knittel, D.; Opwis, K.; Schollmeyer, E. Int. J. Biol. Macromol. 2010, 47, 454.

[53] Costa, E. M.; Silva, S.; Madureira, A. R.; Cardelle-Cobas, A.; Tavaria, F. K.; Pintado, M. M. J. Microbiol. Methods. 2013, 93, 168.

[54] Kulikov, S. N.; Lisovskaya, S. A.; Zelenikhin, P. V.; Bezrodnykh, E. A.; Shakirova, D. R.; Blagodatskikh, I. V.; Tikhonov, V. E. Eur. J. Med. Chem. 2014, 74, 169.

[55] Gurgel-Filho, E. D.; Silva, E. J.; Gomes, B.; Ferraz, C.; Paula, R.; Coutinho-Filho, T.; Souza-Filho, F. Rev. Port. Estomatol. Med. Dent. Cir. Maxilofac. 2012, 53, 153.

[56] Friedman, C. E.; Sandrik, J. L.; Heuer M. A.; Rapp, G. W. J. Endodont. 1977, 3, 304.

[57] Venturi, M.; Di Lenarda, R.; Breschi, L. Int. Endod. J. 2006, 39,648 . 